\title{
Study of Glass Transition and Partial Melting in Melt-crystallized Poly(oxymethylene) by X-ray Small-angle Scattering
}

\author{
Yuji Aoki, Akira Nobuta*, Akio Chiba, and Motozo Kaneko \\ Department of Polymer Science, Faculty of Science, \\ Hokkaido University, Sapporo, Japan.
}

(Received February 8, 1971)

\begin{abstract}
The temperature dependences of the intensity and the long spacing in X-ray small-angle scattering for quenched, $\gamma$-ray irradiated and well annealed poly(oxymethylene)s were measured over a range of temperature from $-120^{\circ} \mathrm{C}$ to the neighbourhood of the melting point. In a range of temperature below $40^{\circ} \mathrm{C}$, the temperature dependence of the peak intensity is due to the difference of the density between the crystalline and the amorphous layers for all samples. Observation of the change of the thermal expansion coefficient in the amorphous layer in the vicinity of $-75^{\circ} \mathrm{C}$ gives direct evidence of glass transition. However, above $40^{\circ} \mathrm{C}$ the temperature dependence of the intensity can not be explained in terms of the density difference. Above $120^{\circ} \mathrm{C}$, partial melting takes place for a well annealed sample and the long spacing increases slightly. On the other hand, for a quenched sample, the annealing effect arises from $120^{\circ} \mathrm{C}$.

KEY WORDS X-ray / Small-angle Scattering / Glass Transition / Melting / Annealing Effect / Poly(oxymethylene)/
\end{abstract}

It has been established that polymers are crystallized in most cases into spherulite aggregates, if crystallized from melt, and that spherulite aggregates made of lamellae in which the chain molecules are folded are never entirely crystalline. It has been proposed on the basis of the density ${ }^{1}$ and the small-angle $\mathrm{X}$-ray ${ }^{2}$ measurements that even "single crystal", crystallized from dilute solution, includes noncrystalline regions. Many authors have proposed that crystalline polymer consists of alternating crystalline and amorphous layers (two phase model). The difference of the density between crystalline and amorphous layers gives rise to $\mathrm{X}$-ray small-angle scattering.

The temperature dependence of X-ray smallangle scattering from crystalline polymers has been studied by several authors. ${ }^{3-13}$ It has been found that the intensity of the small-angle reflection changes almost reversibly with temperature, if the annealing temperature is not exceeded, and in some cases a reversible change of the long spacing is also observed. These phenomena have not been explained fully.

* Present Address: Mitsubishi Petrochemical Company Ltd., Yokkaichi, Mie, Japan.
Geil, et al., ${ }^{8}$ found a reversible change with temperature in the long spacing and the intensity for both bulk and drawn poly(oxymethylene)s (POM). They suggested that the reversible change in the long spacing can only be reconciled with concepts that the thickness of the lamellae of POM is determined by thermodynamic equilibrium considerations $\mathrm{s}^{14-16}$ and/or the long spacing should not be equated by Bragg's law to a periodicity in the sample such as lamellar thickness. They also suggested that the reversible small-angle intensity and spacing changes are a common feature in both bulk and drawn polymers.

Reversible long spacing changes were also observed for single crystal mats of branched polyethylene by Keller, et al. ${ }^{9}$ They suggested that these changes were attributed to reversible changes in the thickness of the lamellar crystals of which the mats were composed.

Kilian, et al., ${ }^{4}$ Nobuta, et al. ${ }^{10}$ and Fischer, et al., ${ }^{11}$ have found that the glass transition which occurs within intercrystalline layers of polyethylene, POM, polybutene-1 can be established by measuring the temperature depend- 
ence of the X-ray small-angle intensity at low temperatures.

In the present paper, the temperature dependences of the intensity and the long spacing in $\mathrm{X}$-ray small-angle scattering for melt-grown POM are studied over a range of temperature from $-120^{\circ} \mathrm{C}$ to the neighbourhood of the melting point. The temperature dependence of the intensity is interpreted in terms of the two-phase model. The glass transition and the partial melting of melt-crystallized POM will be discussed. We also discuss changes in structure of POM caused by annealing and $\gamma$-ray irradiation. The comparison will be performed with previous data of X-ray small-angle scattering.

\section{SAMPLE AND EXPERIMENTAL PROCEDURE}

Three samples of POM used in this work were thin plates of Delrin 150X (E.I. du Pont de Nemours \& Co. Inc.) molded with a laminating press. Sample A was quenched from melt. Sample B was exposed to a beam of $\gamma$-ray of $\mathrm{Co}^{60}$ in air at room temperature. The total irradiation dose was $9.8 \times 10^{6} \mathrm{R}$. Sample $\mathrm{C}$ was annealed at a temperature of $163^{\circ} \mathrm{C}$ for a week. All the samples showed one or two isotropic Debye-Scherrer rings in the X-ray small-angle photograph using pin-hole collimation.

The density was measured with a density gradient tube of xylene- $\mathrm{CCl}_{4}$ system at $25^{\circ} \mathrm{C}$. The volume-averaged crystallinity $\left(x_{\mathrm{cr}}\right)$ was estimated from the density $(\rho)$ using the following equation.

$$
x_{\mathrm{cr}}=\left(\rho-\rho_{\mathrm{a}}\right) /\left(\rho_{\mathrm{c}}-\rho_{\mathrm{a}}\right)
$$

In this paper, we use values of $1.51 \mathrm{~g} / \mathrm{cc}$ and $1.25 \mathrm{~g} / \mathrm{cc}$ as densities of the crystalline, $\rho_{\mathrm{c}}$, and amorphous regions, $\rho_{\mathrm{a}}$, respectively. ${ }^{17}$ Values of these densities will be discussed later in more detail.

The X-ray small-angle scattering scans were taken with a Rigaku-Denki X-ray small-angle diffractometer mounted on a Rigaku-Denki RU-2 rotating anode. The copper radiation was nickel-filtered and detected by a scintillation counter with a pulse-height analyzer. The sample was placed in a heated sample holder. The temperature was measured by a thermocouple mounted in contact with a part of the sample just near the area illuminated by the X-ray beam.

The long spacing determined from the Bragg equation and the density is shown in Table I for each sample.

Table I. Characterization of samples

\begin{tabular}{|c|c|c|c|c|}
\hline Sample & Treatment & $\begin{array}{l}\text { Density, } \\
\text { g/cc }\end{array}$ & $\begin{array}{l}\text { Crystal- } \\
\text { linity, \% }\end{array}$ & $\begin{array}{l}\text { Long } \\
\text { spacing, A }\end{array}$ \\
\hline A & Quenched & 1.422 & 65 & 180 only \\
\hline B & $\begin{array}{l}9.8 \times 10^{6}-\mathrm{R} \\
\text { Irradiated }\end{array}$ & 1.428 & 69 & 180 only \\
\hline $\mathrm{C}$ & $\begin{array}{l}\text { Annealed at } \\
163^{\circ} \mathrm{C} \text { for a } \\
\text { week }\end{array}$ & 1.450 & 77 & 220,110 \\
\hline
\end{tabular}

\section{THEORY}

According to Hosemann ${ }^{18}$ the scattering intensity of a linear lattice as a function of $s=2 \sin \theta / \lambda$ is given by the expression

$$
\begin{aligned}
I(s)= & N\left[\left\langle f^{2}(s)\right\rangle-\langle f(s)\rangle^{2}\right] \\
& +(1 / V)\langle f(s)\rangle^{2} Z(s) *|S(s)|^{2}
\end{aligned}
$$

where $f(s)$ is the particle factor of a single lamella, $Z(s)$ the paracrystalline lattice factor resulting from interlamellar interference, $|S(s)|^{2}$ the shape factor measuring the influence of the finite paracrystal size, $N$ the number of lamellae, $V$ the volume of the paracrystal and $*$ means convolution. The first term yields a diffuse background due to the mean square fluctuation of the particle factor. The discrete intensity distribution is given by the second term representing crystalline interference scattering. In this work, only the second term is considered. For a comparatively large paracrystal the shape factor $|S(s)|^{2}$ is a point-like function compared with $Z(s)$ and thus the intensity is proportional to the product of the square of the particle factor and lattice factor.

$$
I(s)=K\langle f(s)\rangle^{2} Z(s)
$$

For a system consisting of alternating crystalline and amorphous layers the particle factor is

$$
f^{2}(s)=\langle\Delta \rho\rangle^{2}\left[\sin ^{2} \pi s d /(\pi s)^{2}\right]
$$

where $\langle\Delta \rho\rangle$ is the electron density difference between the crystalline and amorphous layers and $d$ is the thickness of the crystalline layer. 
In the case where the fluctuation of the lamellar thickness is small, $\langle f(s)\rangle^{2}$ approximately equals to $f^{2}(s) . \quad Z(s)$ has a maximum value at $s L=n$, where $L$ is the long spacing and $n$ the integer. The intensity of the first diffraction maximum $(s L=1)$ is given by

$$
I_{1}=K_{1}\langle\Delta \rho\rangle^{2} \sin ^{2}(\pi d / L)
$$

whereas that of the second diffraction maximum $(s L=2)$ is

$$
I_{2}=K_{2}\langle\Delta \rho\rangle^{2} \sin ^{2}(2 \pi d / L)
$$

where $K_{1}$ and $K_{2}$ are constants as long as the lattice factor $Z(s)$ is constant, and $d / L$ shows the volume-averaged crystallinity $x_{\mathrm{cr}}$.

In a temperature range where no melting occurs, only $\Delta \rho$ depends on temperature, since the lattice factor $Z(s)$, the long spacing $L$ and the thickness of the crystals $d$ are insensitive to temperature. As the electron density is proportional to the mass density, the temperature dependence of the square root of the relative peak intensity becomes

$$
\begin{aligned}
& \sqrt{I(T) / I\left(T_{0}\right)} \\
& \quad=\Delta \rho(T) / \Delta \rho\left(T_{0}\right)=1+\left(\rho_{\mathrm{a}_{0}} \alpha_{\mathrm{a}}-\rho_{\mathrm{c}_{0}} \alpha_{\mathrm{c}}\right)\left(T-T_{0}\right) / \Delta \rho_{0}
\end{aligned}
$$

where $\Delta \rho_{0}$ is the density difference at a reference temperature $T_{0}^{\circ} \mathrm{C}, \rho_{\mathrm{a}_{0}}$ and $\rho_{\mathrm{c}_{0}}$ the densities of the amorphous and of the crystalline layer at $T_{0}^{\circ} \mathrm{C}$, respectively, and $\alpha_{\mathrm{c}}$ and $\alpha_{\mathrm{a}}$ the thermal expansion coefficients of the crystalline and the amorphous layers, respectively. $\mathrm{Eq} 7$ indicates that the square root of the relative peak intensity is a linear function of $T$ with a slope of $\left(\rho_{\mathrm{a}_{0}} \alpha_{\mathrm{a}}\right.$ $\left.-\rho_{\mathrm{c}_{0}} \alpha_{\mathrm{c}}\right) / \Delta \rho_{0}$.

Let us consider the case that the degree of crystallinity changes with temperature. Then, we have

$$
\begin{aligned}
& I_{1}(T) / I_{1}\left(T_{0}\right) \\
& \quad=\left(\Delta \rho(T) / \Delta \rho\left(T_{0}\right)\right)^{2} \sin ^{2} \pi x_{\mathrm{vr}}(T) / \sin ^{2} \pi x_{\mathrm{cr}}\left(T_{0}\right)(8) \\
& \quad I_{2}(T) / I_{2}\left(T_{0}\right) \\
& \quad=\left(\Delta \rho(T) / \Delta \rho\left(T_{0}\right)\right)^{2} \sin ^{2} 2 \pi x_{\mathrm{sr}}(T) / \sin ^{2} 2 \pi x_{\mathrm{cr}}\left(T_{0}\right)
\end{aligned}
$$

$$
\begin{aligned}
& \left(I_{2}(T) / I_{2}\left(T_{0}\right)\right) /\left(I_{1}(T) / I_{1}\left(T_{0}\right)\right) \\
& \quad=\left(1+\cos 2 \pi x_{\mathrm{vr}}(T)\right) /\left(1+\cos 2 \pi x_{\mathrm{rr}}\left(T_{0}\right)\right)
\end{aligned}
$$

If the crystallinity does not vary with tempera- ture, the temperature dependences of $I_{1}(T) / I_{1}\left(T_{0}\right)$ and $I_{2}(T) / I_{2}\left(T_{0}\right)$ coincide with each other. When the crystallinity changes, $I_{1}(T)$ has a maximum value at $x_{\mathrm{cr}}=1 / 2$ and $I_{2}(T)$ has at $x_{\mathrm{cr}}=3 / 4$. From eq 10 , the temperature dependence of $x_{\mathrm{2r}}$ can be determined. ${ }^{12}$

\section{RESULTS AND DISCUSSION}

Glass Transition of Poly(oxymethylene)

Figure 1 shows the recorder tracings of the small-angle pattern using slit collimation for sample A, B, and C. It was found that $\gamma$-ray irradiation does not make changes in the smallangle pattern, although the scattering intensity decreases. Sample C, which was annealed at $163^{\circ} \mathrm{C}$ for a week, has two peaks in the recorder tracing. The first peak becomes sharp and its maximum angle shifts to a lower angle by annealing. This fact was ascertained by taking photographs using pinhole collimation. The ratio of values of angle at the first and second peak is about two.

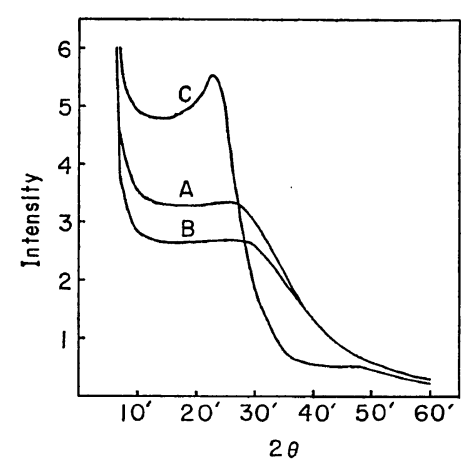

Figure 1. The recorder tracing of the small-angle pattern from poly(oxymethylene): A, quenched sample; $B, 9.8 \times 10^{6}-\mathrm{R}$ irradiated sample; $\mathrm{C}$, annealed sample at $163^{\circ} \mathrm{C}$ for a week.

The square root of the relative peak intensity of the first peak is plotted against temperature in Figure 2 in a temperature range of $90^{\circ} \mathrm{C}$, where the intensity is measured in a unit of the intensity observed at $18^{\circ} \mathrm{C}$. A straight line with a break point in the vicinity of $-75^{\circ} \mathrm{C}$ is found to well describe the temperature dependence of the intensity. It is considered that this break point shows direct evidence for a glass transi- 
Glass Transition and Partial Melting in Poly(oxymethylene)

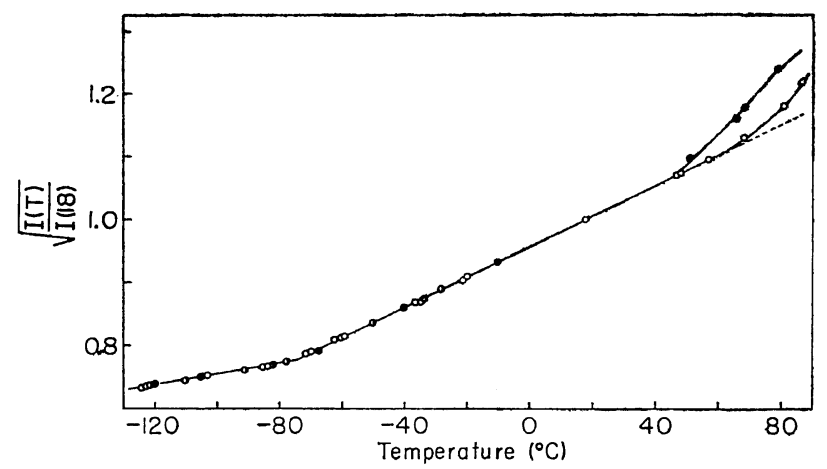

Figure 2. The relative change of the square root of the peak intensity with temperature: sample $\mathrm{A}$; $\rightarrow$, sample $\mathrm{B}$; $\bigcirc$, sample $\mathrm{C}$.

tion in the amorphous layer of POM. The change of the slope corresponds to the abrupt change of $\left(\rho_{\mathrm{a}_{0}} \alpha_{\mathrm{a}}-\rho_{\mathrm{c}_{0}} \alpha_{\mathrm{c}}\right) / \Delta \rho_{0} . \quad \rho_{\mathrm{a}_{0}}, \rho_{\mathrm{c}_{0}}$, and $\Delta \rho_{0}$ are constant values, and $\alpha_{\mathrm{c}}$ has been found to be a constant value of $2 \times 10^{-4} /{ }^{\circ} \mathrm{C}$ at these temperature ranges from the measurement of the temperature dependence of the (110) spacing. ${ }^{19}$ Therefore, it is clear that this change shows the change of $\alpha_{\mathrm{a}}$, that is, glass transition.

Using eq 7 from the slope in a range of temperature from -75 to $40^{\circ} \mathrm{C}$ in Figure 2, a value of $\left(\rho_{\mathrm{a}_{0}} \alpha_{\mathrm{a}}-\rho_{\mathrm{c}_{0}} \alpha_{\mathrm{c}}\right)=6 \times 10^{-4} /{ }^{\circ} \mathrm{C}$ was obtained. $\alpha_{\mathrm{a}}$ was evaluated to be $7.2 \times 10^{-4} /{ }^{\circ} \mathrm{C}$ using $\rho_{\mathrm{c}_{0}}=$ $1.51 \mathrm{~g} / \mathrm{cc}$ from the wide angle data, and assuming $\rho_{\mathrm{a}_{0}}=1.25 \mathrm{~g} / \mathrm{cc}$. This value agrees well with the thermal expansion coefficient of amorphous polymers above glass transition temperature. ${ }^{20}$ This conclusion is also supported by the following facts. Miki, et al. ${ }^{21}$ found by dynamic mechanical measurement that the glass transition temperature of POM is about $-74^{\circ} \mathrm{C}$. Mandelkern, et al. ${ }^{22}$ found that the linear coefficient of the thermal expansion for the solution-grown POM changes in the vicinity of $-85^{\circ} \mathrm{C}$. They suggested that this temperature is glass transition temperature.

It is interesting to note that the glass transition temperature and the thermal expansion coefficient of the amorphous layer in POM are not affected by annealing and $\gamma$-ray irradiation. This fact shows that the amorphous layer between lamellar crystals of POM is fully amorphous and is almost independent of crystalline parts, as reported for melt-crystallized and solution-grown polyethylene by Vonk, et al., ${ }^{23}$ and by Fischer, et al., ${ }^{21}$ respectively.

In a previous paper, ${ }^{24}$ we reported that the degree of crystallinity increases by $\gamma$-ray irradiation. As shown in Table I, the density also increases by $\gamma$-ray irradiation. The intensity of $\mathrm{X}$-ray small-angle scattering decreases with increasing irradiation dose. This can be explained in terms of an idea that the chain-folded lamellae would be transformed into crystals consisting of straight parallel chains that have each end at (001) face by chain scission at their loops.

\section{Partial Melting of Poly(oxymethylene)}

Figure 3 shows the temperature dependence of the square root of the relative peak intensity in a temperature range above $18^{\circ} \mathrm{C}$ for sample C. Open circles denote the first peak and marks of $\times$ denote the second peak. Above $70^{\circ} \mathrm{C}$, the

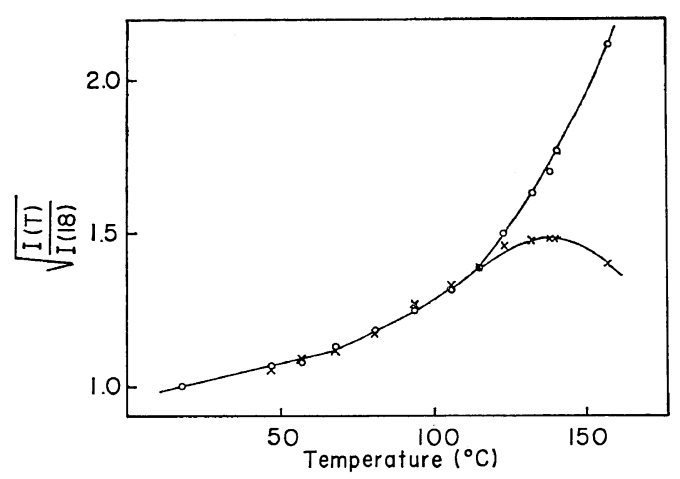

Figure 3. The relative change of the square root of the peak intensity for sample $\mathrm{C}$ : $\bigcirc$, the first peak; $\times$, the second peak. 
intensity of the first peak increases more rapidly with increasing temperature. The temperature dependence of the second peak is almost identical with that of the first peak up to $120^{\circ} \mathrm{C}$, while the deviation occurs above $120^{\circ} \mathrm{C}$. The intensity of the second peak has a maximum value at about $135^{\circ} \mathrm{C}$, while that of the first peak swings up. These changes are almost reversible with temperature.

Eq 10 shows that the temperature dependence of $I_{1}(T) / I_{1}\left(T_{0}\right)$ and $I_{2}(T) / I_{2}\left(T_{0}\right)$ should coincide with each other, if the degree of crystallinity does not vary with temperature. As shown in Figure 3, $I_{1}(T) / I_{1}\left(T_{0}\right)$ and $I_{2}(T) / I_{2}\left(T_{0}\right)$ depart from each other above $120^{\circ} \mathrm{C}$. Therefore, the crystallinity must change in this temperature range. The temperature dependence of the crystallinity was obtained from eq 10, as shown in Figure 4.

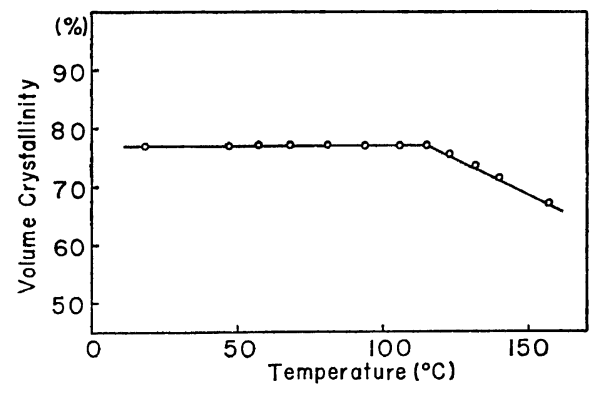

Figure 4. The temperature dependence of the volume-averaged crystallinity evaluated from Figure 3 using eq 10.

The degree of crystallinity decreases gradually and becomes $67 \%$ at $157^{\circ} \mathrm{C}$. At that time the crystallinity of $77 \%$ determined from the density at $25^{\circ} \mathrm{C}$ was used. This value is thought to be reasonable. According to eq $9, I_{2}$ has a maximum at $x_{\mathrm{ur}}=3 / 4$. Since $I_{2}$ has a maximum value at about $135^{\circ} \mathrm{C}$, the crystallinity will be $75 \%$ at about $135^{\circ} \mathrm{C}$. This temperature agrees well with the temperature which gives the crystallinity of $75 \%$. It is considered that the decrease of the crystallinity is due to partial melting, and that crystalline segments near the surface are transformed to amorphous. ${ }^{3}$

This idea of the partial melting is supported by the following facts. The long spacing increases gradually from $120^{\circ} \mathrm{C}$ and becomes several angstroms thicker, as shown in Figure 5. This value is thought to be reasonable, since the calculation shows that the long spacing increases by a value of five angstroms if crystalline segments near the surface are transformed to amorphous in accordance with decrease in the crystallinity from $77 \%$ to $67 \%$.* $^{*}$

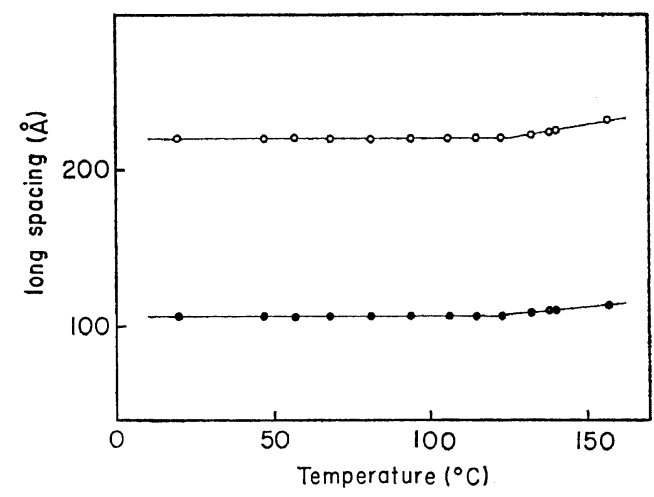

Figure 5. The temperature dependence of the long spacing for sample $\mathrm{C}$ : $\bigcirc$, the first peak; the second peak.

Figure 6 shows that the (100) peak intensity also decreases from $120^{\circ} \mathrm{C}$. Since the Bragg angle of this peak is small, the temperature factor scarcely influences the decrease of the intensity. Accordingly, it is due to the diminution of the crystal volume by the partial melting.

On the other hand, for a quenched sample A the peak intensity of small-angle scattering increases reversibly with temperature up to $120^{\circ} \mathrm{C}$.

* For the two-phase model, the crystal thickness $\left(L_{\text {cr }}\right)$ can be calculated from the long spacing $(L)$ and the volume-averaged crystallinity $\left(x_{\mathrm{er}}\right)$ by the following equation. $L_{\mathrm{cr}}=L x_{\mathrm{cr}}$. The crystal thickness is evaluated to be $170 \AA$ at $120^{\circ} \mathrm{C}(L=220 \AA$, $\left.x_{\mathrm{cr}}=77 \%\right)$ and $154 \AA$ at $159^{\circ} \mathrm{C}\left(L=230 \AA, x_{\mathrm{cr}}=67 \%\right)$. This shows that the crystalline segments of $16 \AA$ along the direction perpendicular to the lamellar plane are transformed to amorphous. When melting takes place, the volume increases by 1.3 times, assuming that the specific volume is 0.88 and $0.68 \mathrm{cc} / \mathrm{g}$ at $159^{\circ} \mathrm{C}$ in the crystalline and the amorphous layers, respectively, from the thermal expansion coefficient data. Then, for the one-dimensional paracrystal, the distance of $16 \AA$ in the crystal region becomes $21 \AA$ in the amorphous region. 
Glass Transition and Partial Melting in Poly(oxymethylene)

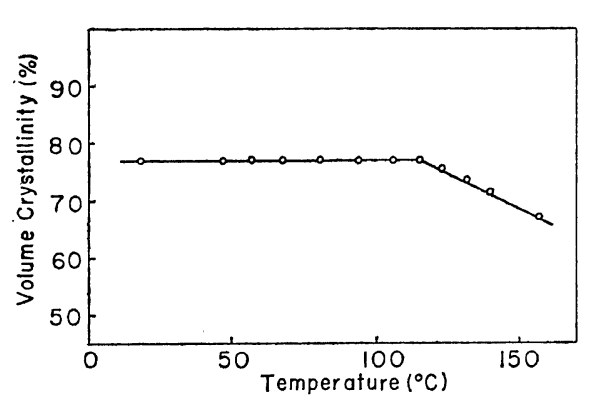

Figure 6. The temperature dependence of the (100) peak intensity for sample $C$.

Above this temperature, the change in intensity becomes irreversible, because of the increase in the crystal thickness. The process of the partial melting may cause the change of the crystal thickness in this case.

From $40^{\circ} \mathrm{C}$ to $120^{\circ} \mathrm{C}$, the intensity of the peak increases with a steeper slope. This can not be explained in terms of the density difference. In a previous paper, ${ }^{19}$ we reported that the thermal expansion coefficient of POM crystal increases abruptly with temperature above $40^{\circ} \mathrm{C}$. Therefore, the slope must decrease at this temperature range, if the thermal expansion coefficient of the amorphous layer remains constant. Until now, it is not clear what is the origin of the increase in intensity in the temperature range from 40 to $120^{\circ} \mathrm{C}$.

Geil, et al.,$^{8}$ measured the temperature dependence of the intensity of X-ray small-angle scattering and long spacing in bulk POM. They found that long spacing and intensity undergo reversible change with temperature and the spacing was seen to remain at an essentially constant value of $200 \AA$ up to a temperature of $125^{\circ} \mathrm{C}$. They also found that when the sample was heated to $159^{\circ} \mathrm{C}$ the long spacing increased to $330 \AA$. They concluded that the reversible $\mathrm{X}$-ray small-angle intensity and spacing changes are common features in both bulk and drawn polymers.

We found that the well-annealed sample shows the increase in long spacing by only several angstroms in the temperature range studied. However, we also found that samples annealed at $150^{\circ} \mathrm{C}$ and at $170^{\circ} \mathrm{C}$ for ten hours show an abrupt increase in long spacing above $120^{\circ} \mathrm{C}$ the same as Geil's data. ${ }^{8}$ The well-annealed sample shows a sharp and strong first peak and second peak. The long spacing of the first peak evaluated from the peak position applying the Bragg's law is just two times larger than that of the second peak. On the other hand, in the sample annealed for ten hours only the first peak found was rather broad. The difference of the temperature dependence of long spacing for the well-annealed sample and not-well annealed sample can be considered as follows. For the well-annealed sample the lamellae are stacked neatly together, whereas for the sample having only one peak the stack of lamellae is rather disturbed. It may be considered that as the partial melting prevails, the peak position apparently shifts at lower angles for the latter sample. Further detailed investigations of this point are now progressing.

\section{CONCLUSIONS}

The two-phase model can be well adopted to explain the temperature dependence of the X-ray small-angle intensity. The temperature dependence of the X-ray small-angle intensity is due to the difference of the density between the crystalline and the amorphous layers at a temperature range from -120 to $40^{\circ} \mathrm{C}$. Glass transition temperature of POM determined by X-ray smallangle scattering method is $-75^{\circ} \mathrm{C}$. These behaviors are not affected by annealing and $\gamma$-ray irradiation. The thermal expansion coefficient of the amorphous layer is about $7.2 \times 10^{-4} /{ }^{\circ} \mathrm{C}$ above glass transition temperature. For a well annealed sample, partial melting takes place above $120^{\circ} \mathrm{C}$ and the long spacing changes only by several angstroms. On the other hand, for a quenched sample, the annealing effect arises from $120^{\circ} \mathrm{C}$. For all the samples studied, at a temperature range from $40^{\circ} \mathrm{C}$ to $120^{\circ} \mathrm{C}$, the temperature dependence of the intensity can not be explained in terms of the density difference. The origin of this behavior has not been clear until now.

Acknowledgement. The authors wish to thank Dr. K. Hikichi for his helpful discussions during the course of this work.

\section{REFERENCES}

1. E. W. Fischer and G. F. Schmidt, Angew. Chem., 
74, 551 (1962).

2. E. W. Fischer, H. Goddar, and G. F. Schmidt, J. Polym. Sci., Part B, 5, 619 (1967).

3. Y. Nukushina, Y. Itoh, and E. W. Fischer, J. Polym. Sci., Part B, 3, 383 (1965).

4. W. Glenz, H. G. Kilian, and F. H. Müller, Kolloid-Z. u. Z. Polymere, 206, 104 (1966).

5. M. Shinomura, A. Chiba, and J. Furuichi, Rep. Progr. Polym. Phys. Japan, 9, 187 (1966).

6. Yu. A. Zubov, V. I. Selikhova, D. Ya. Tsvankin, G. S. Markova, and V. A. Kargin, J. Polym. Sci., Part C, 16, 2215 (1967).

7. J. M. Schultz, W. A. Robinson, and G. M. Pound, J. Polym. Sci., Part A-2, 5, 511 (1967).

8. K. O'Leary and P. H. Geil, J. Macromol. Sci. (Phys.), B1 (1), 147 (1967).

9. J. V. Darkins, P. J. Holdsworth, and A. Keller, Makromol. Chem., 118, 361 (1968).

10. A. Nobuta, A. Chiba, and M. Kaneko, Rep. Progr. Polym. Phys. Japan, 12, 137 (1969).

11. E. W. Fischer, F. Kloos, and G. Lieser, $J$. Polym. Sci., Part B, 7, 845 (1969).

12. T. Hara and T. Seto, Rep. Progr. Polym. Phys. Japan, 12, 189 (1969).

13. M. Maeda, K. Miyasaka, and K. Ishikawa, Kobunshi Kagaku (Chem. High Polymers, Japan),
26, 241 (1969).

14. A. Peterlin, J. Appl. Phys., 31, 1934 (1960).

15. A. Peterlin and E.W. Fischer, Z. Phy., 159, 272 (1960).

16. A. Peterlin and C. Reinhold, J. Polym. Sci., Part A, 3, 2801 (1965).

17. C. F. Hammer, T. A. Koch, and J. F. Whitney, J. Appl. Polym. Sci., 1, 169 (1959).

18. R. Hosemann and S. N. Bagchi, "Direct Analysis of Diffraction by Matter," North-Holland, Amsterdam, 1962.

19. Y. Aoki, A. Chiba, and M. Kaneko, J. Phys. Soc. Japan, 27, 1579 (1969).

20. N. Saito, et al., "Solid State Physics, ed. Seitz and Turnbull,', Vol. 14, Academic Press, New York, N. Y., 1963.

21. K. Miki, S. Yamane and M. Kaneko, "Proceedings of Fifth International Congress on Rheology," Vol. 3, University of Tokyo Press, 1970, p 335.

22. F. S. Stehling and L. Mandelkern, J. Polym. Sci., Part B, 7, 255 (1969).

23. G. Kortleve and C. G. Vonk, Kolloid-Z. u. Z. Polymere, 225, 124 (1968).

24. Y. Aoki, A. Chiba and M. Kaneko, Polymer J., 2, 22 (1971). 